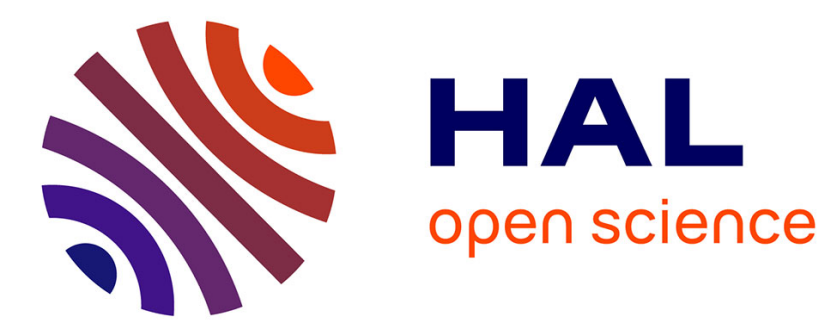

\title{
Divergent above- and below-ground biodiversity pathways mediate disturbance impacts on temperate forest multifunctionality
}

Zuoqiang Yuan, Arshad Ali, Michel Loreau, Fang Ding, Shufang Liu, Anvar

Sanaei, Wangming Zhou, Ji Ye, Fei Lin, Shuai Fang, et al.

\section{To cite this version:}

Zuoqiang Yuan, Arshad Ali, Michel Loreau, Fang Ding, Shufang Liu, et al.. Divergent above- and below-ground biodiversity pathways mediate disturbance impacts on temperate forest multifunctionality. Global Change Biology, 2021, 27 (12), pp.2883-2894. 10.1111/gcb.15606 . hal-03230448

\section{HAL Id: hal-03230448 \\ https://hal.science/hal-03230448}

Submitted on 19 May 2021

HAL is a multi-disciplinary open access archive for the deposit and dissemination of scientific research documents, whether they are published or not. The documents may come from teaching and research institutions in France or abroad, or from public or private research centers.
L'archive ouverte pluridisciplinaire $\mathbf{H A L}$, est destinée au dépôt et à la diffusion de documents scientifiques de niveau recherche, publiés ou non, émanant des établissements d'enseignement et de recherche français ou étrangers, des laboratoires publics ou privés. 


\section{Global Change Biology}

\section{Divergent above- and below-ground biodiversity pathways mediate disturbance impacts on temperate forest multifunctionality}

\begin{tabular}{|c|c|}
\hline Journal: & Global Change Biology \\
\hline Manuscript ID & GCB-21-0185 \\
\hline Wiley - Manuscript type: & Primary Research Articles \\
\hline $\begin{array}{r}\text { Date Submitted by the } \\
\text { Author: }\end{array}$ & 28-Jan-2021 \\
\hline Complete List of Authors: & $\begin{array}{l}\text { Yuan, Zuoqiang } \\
\text { Ali, Arshad; Nanjing Forestry University, College of Forestry } \\
\text { Loreau, Mivhel; Station d'Ecologie Théorique et Expérimentale, CNRS } \\
\text { Ding, Fan; Shenyang Agricultural University, College of Land and } \\
\text { Environment; Dr } \\
\text { Liu, Shufang; Institute of Applied Ecology, Chinese Academy of Sciences, } \\
\text { CAS Key Laboratory of Forest Ecology and Management } \\
\text { Sanaei, Anvar ; Institute of Applied Ecology, Chinese Academy of } \\
\text { Sciences, CAS Key Laboratory of Forest Ecology and Management } \\
\text { Zhou, Wangming; Institute of Applied Ecology, Chinese Academy of } \\
\text { Sciences, CAS Key Laboratory of Forest Ecology and Management } \\
\text { Ye, Ji; CAS Key Laboratory of Forest Ecology and Management, Institute } \\
\text { of Applied Ecology, Chinese Academy of Sciences } \\
\text { Lin, Fei; Institute of Applied Ecology,Chinese Academy of Sciences, } \\
\text { Center for Forest Ecology } \\
\text { Fang, Shuai; CAS Key Laboratory of Forest Ecology and Management, } \\
\text { Institute of Applied Ecology, Chinese Academy of Sciences } \\
\text { Hao, Zhanqiang; Northernwest Polytechnical University, School of } \\
\text { Ecology and Environment } \\
\text { Wang, Xugao; CAS Key Laboratory of Forest Ecology and Management, } \\
\text { Institute of Applied Ecology, Chinese Academy of Sciences } \\
\text { Le Bagousse-Pinguet, Yoann; Aix-Marseille Universite }\end{array}$ \\
\hline Keywords: & $\begin{array}{l}\text { biodiversity, ecosystem functioning, functional traits, disturbance, } \\
\text { natural forests, soil microbes }\end{array}$ \\
\hline Abstract: & $\begin{array}{l}\text { Biodiversity plays a fundamental role in provisioning and regulating } \\
\text { forest ecosystem functions and services. Above-ground (plants) and } \\
\text { below-ground (soil microbes) biodiversity could have asynchronous } \\
\text { change paces to human-driven land-use impacts. Yet we know very little } \\
\text { how they affect the provision of multiple forest functions related to } \\
\text { carbon accumulation, water retention capacity and nutrient cycling } \\
\text { simultaneously (i.e., ecosystem multifunctionality; EMF). We used a } \\
\text { dataset of } 22,000 \text { temperate forest trees from } 260 \text { plots within } 11 \\
\text { permanent forest sites in Northeastern China, which are recovering from } \\
\text { three post-logging disturbances. We assessed the mediating effects of } \\
\text { multiple attributes of plant biodiversity (taxonomic, phylogenetic, } \\
\text { functional, and stand structural) and soil biodiversity (bacteria and fungi) }\end{array}$ \\
\hline
\end{tabular}




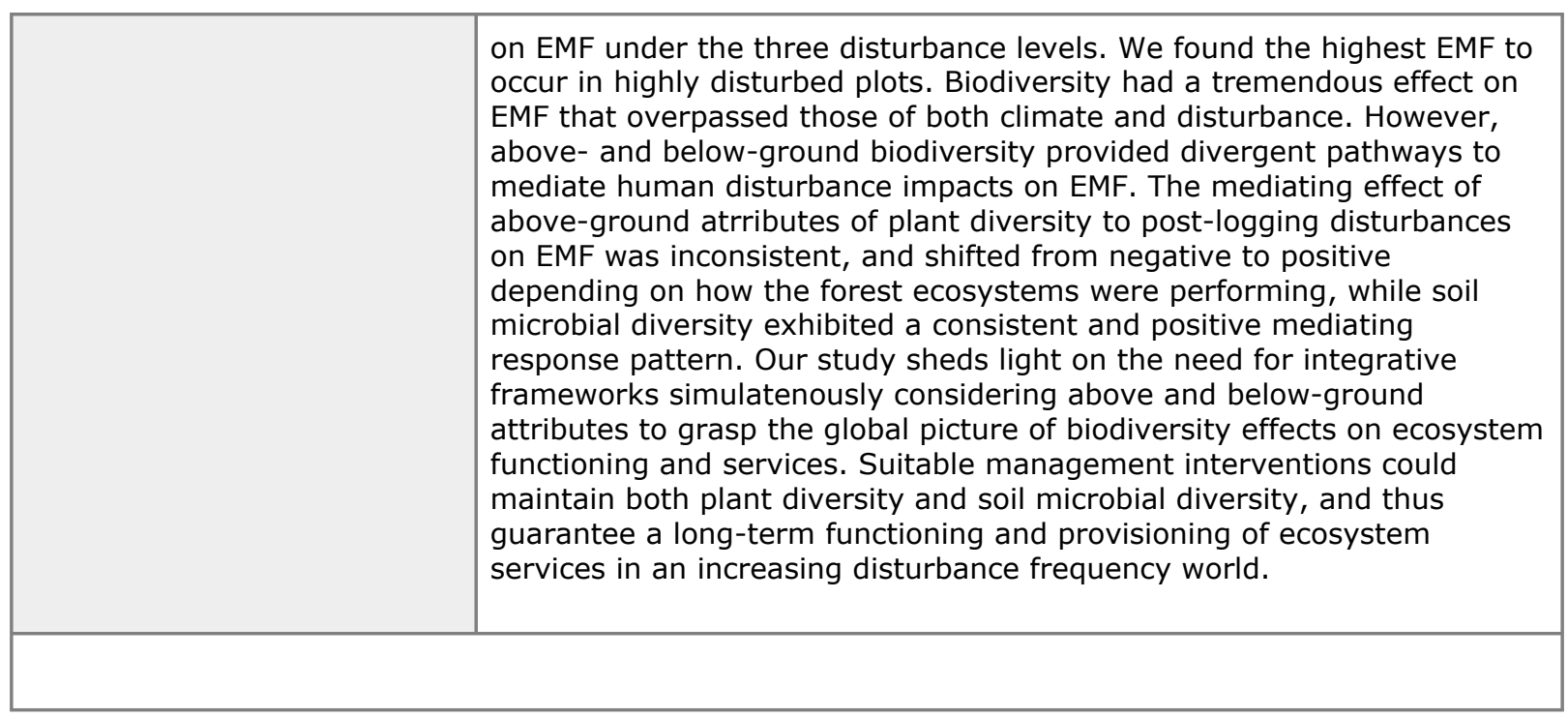


Divergent above- and below-ground biodiversity pathways mediate disturbance impacts on temperate forest multifunctionality

Zuoqiang Yuan ${ }^{1 *}$, Arshad $\mathrm{Ali}^{2,3}$, Michel Loreau ${ }^{4}$, Fang Ding ${ }^{5}$, Shufang Liu ${ }^{1}$, Anvar Sanaei $^{1}$, Wangming Zhou ${ }^{1}$, Ji Ye ${ }^{1}$, Fei Lin ${ }^{1}$, Shuai Fang ${ }^{1}$, Zhanqing Hao ${ }^{7}$, Xugao Wang $^{1}$, Yoann Le Bagousse-Pinguet ${ }^{8}$

${ }^{1}$ CAS Key Laboratory of Forest Ecology and Management, Institute of Applied Ecology, Chinese Academy of Sciences, Shenyang 110164 China

${ }^{2}$ Department of Forest Resources Management, College of Forestry, Nanjing Forestry University, Nanjing 210037, Jiangsu, China

${ }^{3}$ Co-Innovation Center for Sustainable Forestry in Southern China, Nanjing Forestry University, Nanjing 210037, Jiangsu, China

${ }^{4}$ Centre for Biodiversity Theory and Modelling, Theoretical and Experimental Ecology Station, CNRS and Paul Sabatier University, Moulis, France

${ }^{5}$ College of Land and Environment, Shenyang Agriculture University, Shenyang, China

${ }^{6}$ School of Ecology and Environment, Northernwest Polytechnical University, China

${ }^{7}$ Aix Marseille Univ, CNRS, Avignon Université, IRD, IMBE, Technopôle

Arbois-Méditerranée Bât. Villemin - BP 80, F-13545 Aix-en-Provence cedex 04, France.

*Corresponding author: Zuoqiang Yuan (Email: zqyuan@iae.ac.cn;)

Running title : Disturbance drives diversity and functions 
23

24

25

27 be included at the end of the article.

Statement of authorship: substantially to revision.
31

32

33

34

35

36

37

38

39

40

41

42

43

44

ZY, ML and YL conceived the idea; ZY, FD, SL, AS, WZ, JY, FL, SF, ZH and XW conducted the study and collected the data. ZY analysed the data and wrote the first draft with great support from AS and YL, after which all authors contributed

We confirm that, should the manuscript be accepted, the data supporting the results will be archived in an appropriate public repository (e.g. Dryad) and the data DOI will

\section{be included at the end of the article.}

(1)

32

33

34

35

36

37

38

39

40




\section{Abstract}

Biodiversity plays a fundamental role in provisioning and regulating forest ecosystem

functions and services. Above-ground (plants) and below-ground (soil microbes)

biodiversity could have asynchronous change paces to human-driven land-use

impacts. Yet we know very little how they affect the provision of multiple forest

functions related to carbon accumulation, water retention capacity and nutrient

cycling simultaneously (i.e., ecosystem multifunctionality; EMF). We used a dataset

of 22,000 temperate forest trees from 260 plots within 11 permanent forest sites in

Northeastern China, which are recovering from three post-logging disturbances. We

assessed the mediating effects of multiple attributes of plant biodiversity (taxonomic,

phylogenetic, functional, and stand structural) and soil biodiversity (bacteria and

fungi) on EMF under the three disturbance levels. We found the highest EMF to occur

in highly disturbed plots. Biodiversity had a tremendous effect on EMF that

overpassed those of both climate and disturbance. However, above- and below-ground

biodiversity provided divergent pathways to mediate human disturbance impacts on

EMF. The mediating effect of above-ground atrributes of plant diversity to post-logging disturbances on EMF was inconsistent, and shifted from negative to positive depending on how the forest ecosystems were performing, while soil microbial diversity exhibited a consistent and positive mediating response pattern.

Our study sheds light on the need for integrative frameworks simulatenously considering above and below-ground attributes to grasp the global picture of biodiversity effects on ecosystem functioning and services. Suitable management 
67 interventions could maintain both plant diversity and soil microbial diversity, and thus

68 guarantee a long-term functioning and provisioning of ecosystem services in an

69 increasing disturbance frequency world.

70

71 Keywords: biodiversity; ecosystem functioning; functional traits; disturbance; natural

72 forests; soil microbes

73 


\section{Introduction}

Forests harbour much of the terrestrial biodiversity, and provide fundamental functions and services, such as biomass production, nutrient cycling and water retention (Gamfeldt et al., 2013; Pan, Birdsey, Phillips, \& Jackson, 2013). However, human-driven disturbances, such as habitat destruction and resource overexploitation, can cause drastic terrestrial biodiversity loss and ecosystem changes (Newbold et al. 2016, Isbell et al. 2011, Le Provost et al. 2020). For example, selective logging, as a widespread anthropogenic disturbance in natural forest ecosystems, not only exerts critical direct effects on the aboveground biomass stock (Dai et al., 2004), but also on forest biodiversity which includes both above-ground plant diversity and below-ground soil diversity (McGuire et al., 2015), resulting in potentially far-reaching effects on forest multifunctionality (Seidl et al., 2017; Sommerfeld et al., 2018).

As the forest recovery proceeds from the post-logging disturbance, subsequent forest biomass recovers when emerging trees grow to occupy the gaps created by the felled trees, and hence, the loss of forest biomass can be compensated if the forests are left to recover, primarily depending on the magnitude of disturbance intensity (Piponiot et al., 2016). Existing theories have mixed predictions for how the whole functions of a community changes during secondary succession. For instance, MacArthur's minimisation principle suggests that more mature and late-stages communities should become more efficient by minimizing energy wastage, thereby maximizing ecosystem functions (MacArthur, 1984). However, a recent study 
demonstrated that mid-stage communities could be more effective at utilizing resources (Ghedini, Loreau, White, \& Marshall, 2018).

Meanwhile, most of the current studies investigated a lens of human-driven disturbance impacts to focus on either a single or narrow set of biodiversity attributes and ecosystem functions (Le Provost et al., 2020; Newbold et al., 2016). Ample previous work showed that higher species richness could support multiple forest ecosystem functions simultaneously (multifunctionality hereafter; EMF)(Felipe-Lucia et al., 2018; Gamfeldt et al., 2013).However, the diversity of phenotypes (functional trait diversity) and evolutionary lineages (phylogenetic diversity), rather than the number and abundance of species, could also best predict EMF (Gross et al., 2017; Le Bagousse-Pinguet et al., 2019; Yuan et al., 2020), either because functionally distinct species promote the overall resource use efficiency (i.e. the niche complementarity effect) or by including species that strongly influence ecosystem functioning (i.e. the selection effect) (Loreau \& Hector, 2001; Tilman, 1997). Besides, stand structural attributes, such as individual tree size (diameter and/or height) inequality among and within species, could have key implication for the functioning of forest ecosystems (Ali, 2019), by enhancing above-ground light interception and utilization and promoting production efficiency (Gough, Atkins, Fahey, \& Hardiman, 2019). In contrast, the functional identity of dominant species, rather than the diversity per se, is often viewed as the main driver of ecosystem functioning (Prado-Junior et al., 2016; Tobner et al., 2016), following the mass ratio hypothesis (Grime, 1998). Ultimately, below-ground organisms, such as soil microbes, represent a large fraction of 
terrestrial diversity regulating key biogeochemical processes such as nutrient cycling and litter decomposition (Van Der Heijden, Bardgett, \& Van Straalen, 2008), and hence, sustaining EMF (Manuel Delgado-Baquerizo et al., 2020; Wagg, Bender, Widmer, \& van der Heijden, 2014; Yuan et al., 2020). Yet, we still lack an integrative framework aimed at better understanding how multiple attributes of biodiversity, - the richness and abundance of species (taxonomic diversity), the presence of different evolutionary lineages (phylogenetic diversity), the variety of growth forms and resource-use strategies (functional diversity), and the inclusion of above- and below-ground compartments -, and multiple ecosystem functions (J. E. K. Byrnes et al., 2014) are impacted by human disturbances. This largely hampers our ability to improve the scientific understanding of the relationships between biodiversity and ecosystem functioning to formulate sustainable conservation and management policies in the context of global anthropogenic change (Balvanera et al., 2006; Soliveres et al., 2016).

Here, we used a unique dataset of over 22,000 temperate forest trees belonging to 81 species from 260 plots within 11 permanent plots (i.e. sites) to investigate how multiple attributes of above- (i.e. taxonomic, phylogenetic and functional diversities, and stand structure) and below-ground (i.e. soil bacteria and soil fungi) biodiversity simultaneously influence forest EMF under post-logging disturbances. We also considered multiple climate factors as potential drivers of biodiversity and EMF. We address the following questions: 1) Do nearly undisturbed mature forests exhibit the highest EMF compared with the other disturbed forests, following the MacArthur's 
140 (1984) minimisation principle? 2) Do the multiple attributes of biodiversity have 141 differential effects on EMF? and 3) Are the effects of post-logging disturbance on 142 forest EMF equally mediated by above- and below-ground biodiversity pathways?

\section{Materials and Methods}

\section{Study sites and field inventories}

The study was conducted in temperate forests from the Changbai Mountain ( $40^{\circ} 54^{\prime}$ to $44^{\circ} 03^{\prime} \mathrm{N}, 124^{\circ} 47^{\prime}$ to $130^{\circ} 09^{\prime} \mathrm{E}$ ), located in Liaoning and Jilin Provinces in Northeastern China (Fig. S1A in Appendix A). The region is characterized by a temperate continental climate with long cold winters and warm summers. Mean annual temperature and precipitation are $2.8^{\circ} \mathrm{C}$ and $700 \mathrm{~mm}$, respectively. The dominant vegetation type is a mixed forest dominated by the broad-leaved Korean pine (Pinus koraiensis), with high productivity compared to other forests from the same latitude (Stone, 2006). These forests are also hotspots of diversity and home numerous emblematic, but endangered species such as the Siberian tiger (Pantha tigris longipilis L.) and ginseng (Panax ginseng C.A. May) (Shao, Schall, \& Weishampel, 1994). The soils are classified as the Alfisol according to the US soil taxonomy (Yang \& Li, 1985). All studied sites have been protected from intensive human disturbance since 1998, as a result of the implementation of a Natural Forest protection. Thus, forests recovering from disturbances include stands with different successional stages in the study area (Chen et al., 2014). Eleven forest permanent plots ( $>0.8$ ha in size) were established in 2012 and 
162

163

2013 (see Table S1 for details), and have been re-inventoried after five years following a standard field protocol (Yuan et al., 2018). The elevation ranged between 653 and 1020 m.a.s.1.. Soil pH ranged between 5.4 and 7.1 (Table S1). Within each plot (Fig. 1B in Appendix A), all individual trees with a $\mathrm{DBH} \geq 1 \mathrm{~cm}$ in contiguous $20 \times 20$ subplots were tagged, identified, and measured following a standard field protocol (Hao, Zhang, Song, Ye, \& Li, 2007). Their geographical coordinates of all individual trees were also recorded. A total of 22,766 individuals belonging to 81 species, 46 genera, and 26 families were recorded (Yuan et al., 2018).

\section{Quantifying disturbance intensity and climate variables}

The disturbance intensity of each plot was evaluated by counting the number of tree stumps that had been removed in the field using a chainsaw in the 1990s (Kahl \& Bauhus, 2014). In addition, the official records of the Local Forestry Bureau, Jilin and Liaoning Provinces were examined to collect the relevant selective logging data.

Collectively, plots were primarily classified into three disturbance intensity levels, according to the partial harvesting (e.g., thinning, selective harvesting): relatively low $(<10 \%)$, medium (10-20\%), and high (20 30\%) disturbance. Plots with a low disturbance level were distributed in the core zone of the Changbai Mountain Nature Reserve (Fig. 1), which was established in 1960 and is part of the World Biosphere Reserve Network under the Man and the Biosphere Project in 1980 (Shao et al., 1994). Plots with medium and high disturbance levels were primarily located around the residential area. 
We also considered 19 climate variables as potential drivers of EMF, i.e., annual

mean temperature, mean diurnal range, isothermality, temperature seasonality, maximum temperature of the warmest month, minimum temperature of the coldest month, temperature annual range, mean temperature of wettest quarter, mean temperature of driest quarter, mean temperature of warmest quarter, mean temperature of coldest quarter, annual precipitation, precipitation of wettest month, precipitation of driest month, precipitation seasonality (coefficient of variation), precipitation of wettest quarter, precipitation of driest quarter, precipitation of warmest quarter, and precipitation of coldest quarter. These climate variables were collectively extracted from the WorldClim database (Hijmans, Cameron, Parra, Jones, \& Jarvis, 2005), with records from 1970 to 2000 at a 30 -arc second spatial resolution $\left(\sim 1 \mathrm{~km}^{2}\right)$.

\section{Quantifying above- and below-ground biodiversities}

We quantified the taxonomic attributes of aboveground forest diversity using the species richness $(\mathrm{S})$ and Shannon-Wiener diversity indices of tree species $\left(\mathrm{H}_{\mathrm{S}}\right)$. We built up a supertree for all the trees occurred using online software of Phylomatic (http://www.phylodiversity.net) which includes updated time-calibrated branch length of seed plants combining multigene molecular and fossil data (Zanne et al., 2014). Based on the obtained phylogenetic tree, we calculated 1) the Faith's phylogenetic diversity index $\left(\mathrm{PD}_{\mathrm{F}}\right)$, which quantifies the total length of all branches connecting trees in a given subplot (Faith, 1992), and 2) the phylogenetic species variability (PSV) reflecting how phylogenetic relatedness decreases the variance of a hypothetical 
neutral trait (Helmus, Bland, Williams, \& Ives, 2007). We also investigated the role of functional identity and diversity on EMF by computing the community-weighted mean (CWM) of trait values and the functional dispersion index (FD), respectively. The two indices were weighted by the species' relative basal area within a subplot. Functional traits included maximum tree height, wood density, leaf phosphorus content (LPC), leaf nitrogen content (LNC), specific leaf area (SLA) and leaf area (LA), which are related to life-history and nutrient and water-use efficiencies (Pérez-Harguindeguy et al., 2013) (Appendix B). We also quantified the stand structural diversity $\left(\mathrm{H}_{\mathrm{D}}\right)$, using the Shannon-Wiener diversity indices of tree size variations (i.e., tree DBHs) using $2 \mathrm{~cm} \mathrm{DBH}$ as a discrete class (Ali et al., 2016). Meanwhile, individual size inequality $\left(\mathrm{CV}_{\mathrm{D}}\right)$ was quantified as the coefficient of variation for tree $\mathrm{DBH}$ within each subplot, as a proxy for variation in overall tree size. The variability in DBH within natural forests captures the degree of complexity in multilayered stand structure in terms of light capture and use by component species and interacting individuals (reviewed by Ali, 2019).

To evaluate the soil fungal and bacterial diversities, we randomly selected two sampling points from the four midpoints between central point and corners in each 20 $\times 20 \mathrm{~m}$ subplot in August 2018 (Fig. S1C). Five soil cores $(3.8 \mathrm{~cm}$ diameter, $10 \mathrm{~m}$ deep) at each sampling point were collected, pooled and brought to the laboratory for analyses. Each soil sample was further divided into two parts: one for soil microbial diversity measurements (i.e. bacteria and fungi), and the other for soil nutrient analyses after removing roots and stones and air-dried for $24 \mathrm{~h}$. All obtained values 
were averaged to represent mean soil microbial diversity per subplot. For the calculations of Shannon-Wiener diversity indices of soil fungi and bacteria, samples were rarified to 3,000 sequences for bacteria and 2,200 sequences for fungi per soil sample. Summary of diversity variables is provided in Table S1 in Appendix A. More details about the measurements of plant functional traits and soil microbes are provided in Appendix B.

\section{Quantifying ecosystem multifunctionality (EMF)}

We quantified the EMF of the studied forests using nine key functions, i.e., (1) coarse woody productivity (CWP), (2) aboveground biomass of wild edible plants (AGB ${ }_{W}$, (3) soil organic carbon density (SOD), (4) litter layer biomass $\left(\mathrm{B}_{\mathrm{L}}\right)$, (5) water holding capacity of litter layer $\left(\mathrm{WHC}_{\mathrm{L}}\right),(6)$ water holding capacity of the soil $\left(\mathrm{WHC}_{\mathrm{S}}\right),(7)$ soil available nitrogen (AN), (8) soil available phosphorus (AP), and (9) soil available potassium (AK) (Table S1 in Appendix A).

Coarse woody productivity $\left(\mathrm{Mg} \mathrm{ha}^{-1} \mathrm{yr}^{-1}\right)$ was estimated by summing biomass growth and recruitment rates, which were calculated as the increment of stems alive in the last and first inventories, and the biomass of stems recruited into $\mathrm{DBH} \geq 1 \mathrm{~cm}$ between the first and last forest inventories, respectively (Yuan et al., 2019). For the quantification of the aboveground biomass of wild edible plants, we first recognized medicinal and edible shrub species according to the Flora Reipublicae Popularis Sinicae (Hong \& Blackmore, 2015), and then the mean aboveground biomass stock $\left(\mathrm{Mg} \mathrm{ha}^{-1}\right)$ of wild edible plants was quantified using specific species allometric 
models (He, Kang, Fan, Gao, \& Feng, 2011). Soil organic carbon density $\left(\mathrm{kg} \mathrm{m}^{-2}\right)$ of the 0-10 cm layer was calculated based on the formula $C_{d}=\left(1-\theta_{i}\right) \times \rho_{i} \times 0.58 \times$ $c_{i}$, where $\theta_{i}$ is gravel $(>2 \mathrm{~mm})$ content at sample location $i(\%), \rho_{i}$ is soil bulk density in the surface layer $\left(\mathrm{g} \mathrm{cm}^{3}\right)$, and $c_{i}$ is organic matter content in the $i$ th soil sample $(\mathrm{g}$ $\left.\mathrm{kg}^{-1}\right)$.

Litter biomass $\left(\mathrm{Mg} \mathrm{hm}^{-2}\right)$ was determined through the collection of the intact litter layer above soil mineral horizons with a hand spade, after removing the surface dried twigs and herbs. The water-holding capacity (WHC, $\mathrm{Mg} \mathrm{hm}^{-2}$ ) of litters and soils were determined using full drainage methods (Naeth, Bailey, Chanasyk, \& Pluth, 1991). Soil N ( $\left.\mathrm{g} \mathrm{kg}^{-1}\right)$ was determined following the Kjeldahl method. Soil P $\left(\mathrm{g} \mathrm{kg}^{-1}\right)$ was measured by molybdate colorimetry, after digestion in $\mathrm{H}_{2} \mathrm{SO}_{4}-\mathrm{HClO}_{4}$. Total $\mathrm{K}$ (g $\mathrm{kg}^{-1}$ ) was derived using atomic absorption spectrometry. Available $\mathrm{N}$ was alkali digested and was detected using hydrochloric acid titration method, whereas available P was extracted following the method of Mehlich 1(Nelson, Mehlich, \& Winters, 1953). Soil available K was obtained with detection by atomic absorption spectrometry (AAS). Please see detailed measurement approaches in Appendix B. All individual functions were $z$-scored (standardized deviates) and averaged to calculate the forest ecosystem multifunctionality index $\left(\mathrm{EMF}_{\mathrm{A}}\right)(\mathrm{J} . \mathrm{E} . \mathrm{K}$. Byrnes et al., 2014). We also evaluated whether multiple functions are simultaneously performing at a high level using the multiple threshold approach, which calculates the number of functions that reach a given threshold (i.e. the percent of the maximum value of each of the functions measured in the dataset). This maximum is defined as the mean of the 
272 five highest values for each function observed across all study plots. We used

273 multifunctionality-threshold values of $25 \%\left(\mathrm{EMF}_{\mathrm{T} 25}\right), 50 \%\left(\mathrm{EMF}_{\mathrm{T} 50}\right)$ and $75 \%$ $274 \quad\left(\mathrm{EMF}_{\mathrm{T} 75}\right)$.

\section{Statistical analyses}

We first conducted a principal component analysis (PCA) to reduce the multicollinearity in CWM indices and climate variables, separately. The result indicated that the first axis of PCA on CWM indices $\left(\mathrm{CWM}_{\mathrm{PC} 1}\right)$ explained $56.9 \%$ of the total variation in CWM variables, mainly reflecting taller trees (high CWM of height) but lower CWM of SLA and LNC (i.e., conservative strategy). The first axis of PCA on climate variables $\left(\mathrm{Clim}_{\mathrm{PC} 1}\right)$ accounted for $67.1 \%$ of the variation representing increasing temperature and precipitation gradients (Table S2).

We tested the effects of disturbance on EMF and individual functions separately, as well as on above- (i.e. taxonomic, phylogenetic, functional and stand structure) and $\mathrm{CV}_{\mathrm{D}}$, to avoid multicollinearity issues (see Fig. S2). Hence, nine variables including 
below-ground diversity indices $\left(\mathrm{H}_{\mathrm{B}}\right.$ and $\left.\mathrm{H}_{\mathrm{F}}\right)$, one composite climate variable $\left(\mathrm{Clim}_{\mathrm{PC} 1}\right)$, and disturbance levels were included into the multiple regression models for predicting EMF. The disturbance levels were treated as an ordinal categorical variable (i.e. a regular numeric variable) and were coded as 1 (low), 2 (medium), and 3 (high). Since all predictors and response variables were standardized after min-max normalization, an analogue of the variance decomposition analysis was applied to obtain the relative importance of each predictor on a comparable scale, which can be simply calculated as the ratio between its standardized regression coefficient and the sum of all coefficients, and expressed in \% (Le Bagousse-Pinguet et al., 2019). The obtained relative importance of predictors was grouped into five identifiable variance fractions: (i) above-ground diversity, (ii) below-ground diversity, (iii) climate, (iv) disturbance levels and (v) unexplained variance.

Finally, we used a piecewise structural equation modeling (pSEM) to investigate direct and biodiversity-mediated effects of disturbance intensities on the averaged EMF-index, EMF-thresholds and individuals ecosystem functions. We used site (i.e. 11 plots) as a random factor in pSEM. Since we had multiple candidate variables to use in pSEM, we included those variables of above- and below-ground diversity which had the highest standardized effect on EMF in multiple linear regression models. The model fit of pSEM was assessed using the Fisher's $\mathrm{C}$ statistic, i.e., the model was considered to have adequate fit to the data when the model had a Fisher's C statistic with $P>0.05$ (Shipley, 2009). The conditional $\left(R_{\mathrm{c}}^{2}\right)$ and marginal $R^{2}\left(R_{\mathrm{m}}^{2}\right)$ were calculated for each of the dependent variables (Nakagawa \& Schielzeth, 2013). 
We computed the Pearson correlations between pairs of individuals functions

and their relationships with $\mathrm{EMF}_{\mathrm{A}}$, aiming to assess the synergies (positive) or trade-offs (negative) between forest functions. All data analyses were conducted in $\mathrm{R}$ 3.6.0 (R Development Core Team, 2019). Phylogenetic and functional diversity indices were calculated using the picante (Kembel et al., 2010) and FD packages (Laliberte \& Legendre, 2010), respectively. EMF indices were calculated using the multifunc package (J. Byrnes, 2014). Multiple linear mixed models and pSEM analyses were performed in nlme (Pinheiro et al., 2017) and piecewise SEM (Lefcheck, 2016) packages, respectively.

\section{Results}

Highly disturbed plots exhibited the highest EMF, even at higher thresholds (Fig. 1A). In addition, five of the nine individual functions (i.e., $\mathrm{SOD}, \mathrm{WHC}_{\mathrm{S}}, \mathrm{AN}, \mathrm{AP}$, and $\mathrm{AK}$ ) measured in highly disturbed plots were significantly higher than in low disturbed plots. In contrast, $\mathrm{AGB}_{\mathrm{W}}$ was higher in low disturbed plots, whereas $\mathrm{CWP}, \mathrm{B}_{\mathrm{L}}$, and $\mathrm{WHC}_{\mathrm{L}}$ did not show significant differences among the three levels of disturbance (Fig. S3). As such, plant species richness (S), Shannon-Wiener diversity $\left(\mathrm{H}_{\mathrm{S}}\right)$, Faith's phylogenetic diversity $\left(\mathrm{PD}_{\mathrm{F}}\right)$, and soil microbe diversity $\left(\mathrm{H}_{\mathrm{B}} \& \mathrm{H}_{\mathrm{F}}\right)$ were higher in highly disturbed plots, whereas functional trait diversity (FD) and identity $\left(\mathrm{CWM}_{\mathrm{PC} 1}\right)$ and stand structural attributes $\left(\mathrm{H}_{\mathrm{D}}\right.$ and $\left.\mathrm{CV}_{\mathrm{D}}\right)$ were higher in low disturbed plots (Fig. 1B). 
the variations in $\mathrm{EMF}_{\mathrm{A}}, \mathrm{EMF}_{\mathrm{T} 25}, \mathrm{EMF}_{\mathrm{T} 50}$ and $\mathrm{EMF}_{\mathrm{T} 75}$, respectively (Fig.2). The biodiversity indices explained $45 \%$ on average [26-58\%] of the variations in EMF, while climate and disturbance together explained on average $7 \%[0.4-15 \%]$. The cumulative above-and below-ground diversity accounted for about $26.0 \%$ [17.5-39.4\%] and $18.9 \%$ [8.1-28.8\%] of the variations in EMF, respectively. Individual tree size variation $\left(\mathrm{CV}_{\mathrm{D}}\right)$ and soil bacterial diversity $\left(\mathrm{H}_{\mathrm{B}}\right)$ were selected as the best predictors of above- and below-ground diversity, explaining up to $11.3 \%$ [4.6-19.7\%] and 6.0\% [2.0-9.9\%] of the accounted variance, respectively (Fig.2). Since there was no significant relationship between composite climate factors $\left(\mathrm{Clim}_{\mathrm{PC} 1}\right)$ and EMF, and hence, we did not include $\mathrm{Clim}_{\mathrm{PC} 1}$ in the pSEM analysis (Fig.2).

The tested pSEM models showed that disturbance had significant positive direct effects on EMF, irrespective of the EMF threshold considered (Fig. 3). However, our models also showed opposite indirect effects of disturbances on EMF, highlighting the occurrence of contrasting biodiversity-mediated pathways. While both above- and belowground diversity attributes had direct positive effects on EMF, their mediating effects were in partial contrast, i.e., negative for aboveground diversity and positive for belowground diversity. Furthermore, the negative mediating effect of aboveground diversity on EMF increased with higher thresholds $(\beta=0.02$ to 0.19 ), highlighting a stronger negative pathway occurring when functions performed at higher rates (Fig. 3). In order to complement the results from main pSEMs (Fig. 3), the correlation between forest functions is provided in Fig. S4, whereas pSEMs for 
tested single forest functions are provided in Fig. S5.

\section{Discussion}

Our study offers an integrative framework aimed at exploring how multiple attributes of above-ground (taxonomic, phylogenetic, functional, and stand structure) and below-ground (soil bacterial and fungal diversities) biodiversities simultaneously influence the EMF of temperate forests recovering from post-logging disturbances. The effects of biodiversity on EMF were two-fold higher than those of both climate and disturbances together, expanding to previous findings on individual function such as productivity to EMF (Duffy et al. 2017). However, our results also show evidence for divergent above- and below-ground biodiversity pathways in mediating disturbance impacts on EMF. Hence, this study highlights the necessity of considering the multi-dimensional role of biodiversity to better grasp its complex effects on the functioning of terrestrial ecosystems in a changing world.

Maximum EMF was found in disturbed forests rather than relatively undisturbed mature forests. Our result thus departs from the MacArthur's (1970) minimisation principle, suggesting that more mature and late-stage communities should become more efficient by minimising energy wastage and thus maximizing ecosystem functioning. Rather, our result reminds the recent study of (Ghedini et al., 2018) who observed that mid-stage communities could be more efficient at utilizing resources. Specifically, forest canopy removal by sawlogs and timber harvesting indeed could result in tree density and forest biomass decline (Yuan et al., 2018), but our finding shows that relatively high disturbed forests could promote EMF by increasing soil 
382

383

carbon storage, nutrient availability, and water retention capability, and hence, supporting the notion that suitable forest practice such as thining could achieve the best combination of high wood yield and nutrients reserves (Gong, Tan, Liu, \& Xu, 2021; Schwaiger, Poschenrieder, Biber, \& Pretzsch, 2019; Thornley \& Cannell, 2000). One possible mechanistic explanation is that timber harvest will lead to more plant residues entering the soil, and more light and precipitation to reach the floor, which in turn may increase the litter decomposition rate and nutrient cycling (Huang, Li, \& Su, 2020; Simonin, Kolb, Montes-Helu, \& Koch, 2007). However, there was no significant difference in woody production among the three levels of disturbance, implying that subsequent forest biomass recovers when emerging trees grow to occupy the gaps created by the falled trees, and hence, the loss of forest biomass can be compensated if the forests are left to recover, primarily depending on the magnitude of disturbance intensity (Piponiot et al., 2016). Collectively, compared with the relative pristine or unmanaged stands, the soil physicochemical properties, such as organic matter and available nitrogen, maximal water retention, and total porosity, of natural mixed stands with low and medium management intensities were significantly increased after 10 years restoration (WU et al., 2008).

Stand structural diversity was the main above-ground biodiversity attribute to promote EMF, particularly at higher multifunctionality-thresholds. This result confirms the key role of stand structure for forest EMF, as previosuly shown for individual functions (e.g. productivity) (Ali et al., 2016; Gough, Atkins, Fahey, Hardiman, \& LaRue, 2020). Forests with complex stand structure attribute such as 
404

405

406

407

408

409

410

411

412

higher tree size variations, mainly reflecting the degree of heterogeneity in vegetation density, could sustain higher EMF likely through optimizing space, resources and understory microclimatic conditions (Hardiman et al., 2013; Jucker, Bouriaud, Coomes, \& Baltzer, 2015). For instance, higher individual size inequality $\left(\mathrm{CV}_{\mathrm{D}}\right)$ could promote heterogeneity in branch and leaf density and morphology, resulting in higher light use efficiency (Ali, 2019; Yachi \& Loreau, 2007). For instance, our analysis also indicates that more complex communities could lead to faster shrub species growth and biomass accumulation (Fig.S5B).

Considering multiple above-ground biodiversity attributes showed contrasted responses to post-logging disturbance, ultimately leading to positive, neutral and negative effects on EMF (Le Bagousse-Pinguet et al., 2019). Although timber harvesting could cause a reduction in stand structural diversity due to large stems removal, it could promote species diversity by creating forest gaps in which higher light resources might be available for saplings or colonizing seedlings (Molino \& Sabatier, 2001). Gaps could promote higher tree species diversity through the niche partitioning of more greatly contrasting and frequently created resources and/or density effect (Sipe \& Bazzaz, 1995). These gaps are expected to be occupied by early-successional, light-demanding species (Poorter \& Bongers, 2006). Generally, forest gaps are also expected to be primarily filled by the inclusion of by chance species rather than by best-adapted species because of the stochastic availability of gaps and limited recruitment of juveniles leading to slow competitive exclusion and enable the coexistence of more plant species (Brokaw \& Busing, 2000). Interestingly, 
our results show that the disturbance-induced increase in species richness does not lead to higher functional trait diversity, implying the high functional redundancy in the above-ground species composition. Therefore, ignoring the contrasting effects of land-use impacts on a variety of biodiversity attributes, such as taxonomic, phylogenetic, functional, and stand structural diversity, will likely bias our ability to predict the functional consequences of biodiversity decline (Le Bagousse-Pinguet et al., 2019).In contrast of the above-groung biodiversity attributes considered, high soil bacterial diversity consistently promoted EMF irrespective of the multifunctionlaity-threshold considered, while soil diversity is often viewed to drive EMF mainly at low thresholds (M. Delgado-Baquerizo et al., 2016; Wagg et al., 2014). Soil bacteria diversity is a main driver for maintaining EMF in many terrestrial ecosystems (M. Delgado-Baquerizo et al., 2016; Wagg et al., 2014; Wang et al., 2019; Yuan et al., 2020) through maintaining key ecological processes such as nutrient cycling and decomposition (Manuel Delgado-Baquerizo et al., 2020; Van Der Heijden et al., 2008). A recent global survey and microcosm experiment revealed that the positive impact of soil biodiversity on EMF can be maintained across biomes after accounting for important ecosystem factors such as climate and plant attributes (Manuel Delgado-Baquerizo et al., 2020). Higher diversity of soil organisms, such as bacteria and fungi, are the major controllers of EMF by fine-tuning nutrient supply and the distribution of resources, thereby promoting high rates of material processing in terrestrial ecosystems which supplies substrate to other important soil organisms involved in nutrient cycling and releases soil nutrients to above-ground communities 
448 (Maron et al., 2018; Wardle et al., 2004). One of the important findings of this study 449 is that the relative contribution of stand structural attributes on EMF increased with the increasing thresholds levels of EMF, which can be viewed as a superior predictor 451 of ecosystem functioning, as has been shown for individual functions (e.g. productivity) (Ali et al., 2016; Gough et al., 2020). Forests with complex stand structure attribute such as higher tree size variations, mainly reflecting the degree of heterogeneity in vegetation density, sustaining higher EMF likely through optimizing space and understory microclimatic conditions (Hardiman et al., 2013; Jucker et al., 2015). As the individual size inequality $\left(\mathrm{CV}_{\mathrm{D}}\right)$ increases, niche differentiation among and plasticity within trees probably augment heterogeneity in branch and leaf density and morphology, resulting in more efficient light intercept and utilize across a range of light conditions (Ali, 2019; Yachi \& Loreau, 2007). For instance, our analysis also indicates that more complex communities could lead to faster shrub species growth and biomass accumulation (Fig.S5B).

Our study provides observational evidence that post-logging disturbances (from low to high level) could enhance forest multifunctionality and below-ground biodiversity, while simultaneously declining above-ground biodiversity. While certain attributes of above-ground plant diversity can impede EMF, above-ground stand structural and soil microbial diversity attributes appears as important biodiversity facets to promote forest ecosystem multifunctionality. Hence, managing forest ecosystems to maximize above-ground biodiversity, such as higher species richness, may not necessarily maximize a particular subset of functions. In other words, 
470

471

472

ecosystem service provisioning cannot be solely replaced by the protection of a high above-ground stand diversity (Felipe-Lucia et al., 2018; Meyer et al., 2018). This study underlines that maintaining multifunctional forests through a suitable level of management or disturbance intensity may allow for higher biodiversity and ecosystem services on which human beings are dependent. Hence, we argue that the inclusion of soil biodiversity and disturbance levels should be considered as decisive components of the management decision-making policies (Manuel Delgado-Baquerizo et al., 2020; Huang et al., 2020).

\section{Acknowledgements}

This work was supported by Strategic Priority Research Program of the Chinese Academy of Sciences (XDA23080302 \& XDB 31030000), Key Research Program of Frontier Sciences (ZDBS-LY-DQC019) of the Chinese Academy of Sciences, the National Natural Science Foundation of China (31730015, 31961133027 and 41671050) and Youth Innovation Promotion Association CAS (2017241). A. Ali is supported by Special Project for Introducing Foreign Talents - Jiangsu "Foreign Expert Hundred People Program" (Grant No. BX2019084), and Metasequoia Faculty Research Startup Funding at Nanjing Forestry University (Grant No. 163010230). M.L. was supported by the TULIP Laboratory of Excellence (ANR-10-LABX-41). The authors have no conflict of interest to declare. YLB-P was supported by a Marie 
492

493

494

495

496

497

498

499

500

501

502

503

504

505

506

507

508

509

510

511

512

513

514

515

516

517

518

519

520

521

522

523

524

525

526

527

528

529

Program Horizon 2020 (DRYFUN Project 656035). We are grateful to the Dr.

Manuel Delgado-Baquerizo and Tommaso Jucker for valuable comments on earlier

versions. The authors have no conflict of interest to declare.

\section{References}

Ali, A. (2019). Forest stand structure and functioning: Current knowledge and future challenges. Ecological Indicators, 98, 665-677.

Ali, A., Yan, E.-R., Chen, H. Y. H., Chang, S. X., Zhao, Y.-T., Yang, X.-D., \& Xu, M.-S. (2016). Stand structural diversity rather than species diversity enhances aboveground carbon storage in secondary subtropical forests in Eastern China. Biogeosciences, 13(16), 4627-4635. doi:10.5194/bg-13-4627-2016

Balvanera, P., Pfisterer, A. B., Buchmann, N., He, J. S., Nakashizuka, T., Raffaelli, D., \& Schmid, B. (2006). Quantifying the evidence for biodiversity effects on ecosystem functioning and services. Ecol Lett, 9(10), 1146-1156.

Brokaw, N., \& Busing, R. T. (2000). Niche versus chance and tree diversity in forest gaps. Trends in ecology \& evolution, 15(5), 183-188.

Byrnes, J. (2014). multifunc: Analysis of Ecological Drivers on Ecosystem Multifunctionality R Package Version 0.6.2 R Foundation for Statistical Computing, Vienna,.

Byrnes, J. E. K., Gamfeldt, L., Isbell, F., Lefcheck, J. S., Griffin, J. N., Hector, A., . . Freckleton, R. (2014). Investigating the relationship between biodiversity and ecosystem multifunctionality: challenges and solutions. Methods in Ecology and Evolution, 5(2), 111-124. doi:10.1111/2041-210x.12143

Chen, L., Wang, L., Baiketuerhan, Y., Zhang, C., Zhao, X., \& von Gadow, K. (2014). Seed dispersal and seedling recruitment of trees at different successional stages in a temperate forest in northeastern China. Journal of Plant Ecology, 7(4), 337-346. doi:10.1093/jpe/rtt024

Dai, L., Chen, G., Deng, H., Ji, L., Hao, Z., \& Wang, Q. (2004). Structure characteristics and health distance assessment of various disturbed communities of Korean pine and broadleaved mixed forest in Changbai Mountains. Chinese Journal of Applied Ecology, 10(15), 1750-1754.

Delgado-Baquerizo, M., Maestre, F. T., Reich, P. B., Jeffries, T. C., Gaitan, J. J., Encinar, D., . . Singh, B. K. (2016). Microbial diversity drives multifunctionality in terrestrial ecosystems. Nat Commun, 7, 10541. doi:10.1038/ncomms10541

Delgado-Baquerizo, M., Reich, P. B., Trivedi, C., Eldridge, D. J., Abades, S., Alfaro, F. D., . . Singh, B. K. (2020). Multiple elements of soil biodiversity drive ecosystem functions across biomes. Nature Ecology \& Evolution, 4(2), 210-220. doi:10.1038/s41559-019-1084-y

Faith, D. P. (1992). Conservation evaluation and phylogenetic diversity. Biological conservation, 61(1), 1-10.

Felipe-Lucia, M. R., Soliveres, S., Penone, C., Manning, P., van der Plas, F., Boch, S., . . Allan, E. (2018). 
Multiple forest attributes underpin the supply of multiple ecosystem services. Nat Commun, 9(1), 4839. doi:10.1038/s41467-018-07082-4

Gamfeldt, L., Snall, T., Bagchi, R., Jonsson, M., Gustafsson, L., Kjellander, P., . . Bengtsson, J. (2013). Higher levels of multiple ecosystem services are found in forests with more tree species. Nat Commun, 4, 1340. doi:10.1038/ncomms2328

Ghedini, G., Loreau, M., White, C. R., \& Marshall, D. J. (2018). Testing MacArthur's minimisation principle: do communities minimise energy wastage during succession? Ecol Lett, 21(8), 1182-1190.

Gong, C., Tan, Q., Liu, G., \& Xu, M. (2021). Forest thinning increases soil carbon stocks in China. Forest Ecology and Management, 482, 118812.

Gough, C. M., Atkins, J. W., Fahey, R. T., \& Hardiman, B. S. (2019). High rates of primary production in structurally complex forests. Ecology.

Gough, C. M., Atkins, J. W., Fahey, R. T., Hardiman, B. S., \& LaRue, E. A. (2020). Community and structural constraints on the complexity of eastern North American forests. Global Ecology and Biogeography.

Grime, J. (1998). Benefits of plant diversity to ecosystems: immediate, filter and founder effects. Journal of Ecology, 86(6), 902-910.

Gross, N., Le Bagousse-Pinguet, Y., Liancourt, P., Berdugo, M., Gotelli, N. J., \& Maestre, F. T. (2017). Functional trait diversity maximizes ecosystem multifunctionality. Nature Ecology \& Evolution, 1(5), 1-9.

Hao, Z., Zhang, J., Song, B., Ye, J., \& Li, B. (2007). Vertical structure and spatial associations of dominant tree species in an old-growth temperate forest. Forest Ecology and Management, 252(1-3), 1-11.

Hardiman, B. S., Gough, C. M., Halperin, A., Hofmeister, K. L., Nave, L. E., Bohrer, G., \& Curtis, P. S. (2013). Maintaining high rates of carbon storage in old forests: a mechanism linking canopy structure to forest function. Forest Ecology and Management, 298, 111-119.

He, L., Kang, X., Fan, X., Gao, Y., \& Feng, Q. (2011). Estimation and analysis of understory shrub biomass in Changbai Mountains. Journal of Nanjing Forestry University (Natural Sciences Edition), 35(5), 45-50.

Helmus, M. R., Bland, T. J., Williams, C. K., \& Ives, A. R. (2007). Phylogenetic measures of biodiversity. The American Naturalist, 169(3), E68-E83.

Hijmans, R. J., Cameron, S. E., Parra, J. L., Jones, P. G., \& Jarvis, A. (2005). Very high resolution interpolated climate surfaces for global land areas. International Journal of Climatology: A Journal of the Royal Meteorological Society, 25(15), 1965-1978.

Hong, D.-Y., \& Blackmore, S. (2015). Plants of China: A companion to the Flora of China: Cambridge University Press.

Huang, X., Li, S., \& Su, J. (2020). Thinning enhances ecosystem multifunctionality via increase of functional diversity in a Pinus yunnanensis natural secondary forest.

Jucker, T., Bouriaud, O., Coomes, D. A., \& Baltzer, J. (2015). Crown plasticity enables trees to optimize canopy packing in mixed-species forests. Functional Ecology, 29(8), 1078-1086. doi:10.1111/1365-2435.12428

Kahl, T., \& Bauhus, J. (2014). An index of forest management intensity based on assessment of harvested tree volume, tree species composition and dead wood origin. Nature Conservation, 7. doi:10.3897/natureconservation.7.7281 
Kembel, S. W., Cowan, P. D., Helmus, M. R., Cornwell, W. K., Morlon, H., Ackerly, D. D., .. Webb, C. O. (2010). Picante: R tools for integrating phylogenies and ecology. Bioinformatics, 26(11), 1463-1464. doi:10.1093/bioinformatics/btq166

Laliberte, E., \& Legendre, P. (2010). A distance-based framework for measuring functional diversity from multiple traits. Ecology, 91(1), 299-305. doi:Doi 10.1890/08-2244.1

Le Bagousse-Pinguet, Y., Soliveres, S., Gross, N., Torices, R., Berdugo, M., \& Maestre, F. T. (2019). Phylogenetic, functional, and taxonomic richness have both positive and negative effects on ecosystem multifunctionality. Proc Natl Acad Sci U S A, 116(17), 8419-8424. doi:10.1073/pnas.1815727116

Le Provost, G., Badenhausser, I., Le Bagousse-Pinguet, Y., Clough, Y., Henckel, L., Violle, C., ... Gross, N. (2020). Land-use history impacts functional diversity across multiple trophic groups. Proceedings of the National Academy of Sciences, 117(3), 1573-1579.

Lefcheck, J. (2016). piecewiseSEM: Piecewise structural equation modelling in $r$ for ecology, evolution, and systematics. Methods in Ecology and Evolution, 7, 573-579.

Loreau, M., \& Hector, A. (2001). Partitioning selection and complementarity in biodiversity experiments. Nature, 412(6842), 72-76. doi:10.1038/35083573

MacArthur, R. H. (1984). Geographical ecology: patterns in the distribution of species: Princeton University Press.

Maron, P. A., Sarr, A., Kaisermann, A., Leveque, J., Mathieu, O., Guigue, J., . . Ranjard, L. (2018). High Microbial Diversity Promotes Soil Ecosystem Functioning. Appl Environ Microbiol, 84(9). doi:10.1128/AEM.02738-17

McGuire, K. L., D'Angelo, H., Brearley, F. Q., Gedallovich, S. M., Babar, N., Yang, N., . . Fierer, N. (2015). Responses of soil fungi to logging and oil palm agriculture in Southeast Asian tropical forests. Microb Ecol, 69(4), 733-747. doi:10.1007/s00248-014-0468-4

Meyer, S. T., Ptacnik, R., Hillebrand, H., Bessler, H., Buchmann, N., Ebeling, A., . . Weisser, W. W. (2018). Biodiversity-multifunctionality relationships depend on identity and number of measured functions. Nat Ecol Evol, 2(1), 44-49. doi:10.1038/s41559-017-0391-4

Molino, J.-F., \& Sabatier, D. (2001). Tree diversity in tropical rain forests: a validation of the intermediate disturbance hypothesis. Science, 294(5547), 1702-1704.

Naeth, M., Bailey, A., Chanasyk, D., \& Pluth, D. (1991). Water holding capacity of litter and soil organic matter in mixed prairie and fescue grassland ecosystems of Alberta. Journal of Range management, 13-17.

Nakagawa, S., \& Schielzeth, H. (2013). A general and simple method for obtaining R2 from generalized linear mixed-effects models. Methods in Ecology and Evolution, 4(2), 133-142. doi:10.1111/j.2041-210x.2012.00261.x

Nelson, W., Mehlich, A., \& Winters, E. (1953). The development, evaluation, and use of soil tests for phosphorus availability. Agronomy, 4(2), 153-188.

Newbold, T., Hudson, L. N., Arnell, A. P., Contu, S., De Palma, A., Ferrier, S., . . Phillips, H. R. (2016). Has land use pushed terrestrial biodiversity beyond the planetary boundary? A global assessment. Science, 353(6296), 288-291.

Pan, Y., Birdsey, R. A., Phillips, O. L., \& Jackson, R. B. (2013). The structure, distribution, and biomass of the world's forests. Annual Review of Ecology, Evolution, and Systematics, 44, 593-622.

Pérez-Harguindeguy, N., Díaz, S., Garnier, E., Lavorel, S., Poorter, H., Jaureguiberry, P., . . Gurvich, D. (2013). New handbook for standardised measurement of plant functional traits worldwide. 
Australian Journal of botany, 61(3), 167-234.

Pinheiro, J., Bates, D., DebRoy, S., Sarkar, D., Heisterkamp, S., Van Willigen, B., \& Maintainer, R. (2017). Package 'nlme'. Linear and nonlinear mixed effects models, version, 3(1).

Piponiot, C., Sist, P., Mazzei, L., Peña-Claros, M., Putz, F. E., Rutishauser, E., . . Baraloto, C. (2016). Carbon recovery dynamics following disturbance by selective logging in Amazonian forests. Elife, 5, e21394.

Poorter, L., \& Bongers, F. (2006). Leaf traits are good predictors of plant performance across 53 rain forest species. Ecology, 87(7), 1733-1743.

Prado-Junior, J. A., Schiavini, I., Vale, V. S., Arantes, C. S., van der Sande, M. T., Lohbeck, M., . . . Nardoto, G. B. (2016). Conservative species drive biomass productivity in tropical dry forests. Journal of Ecology, 104(3), 817-827. doi:10.1111/1365-2745.12543

R Development Core Team. (2019). R version 3.6.0. Vienna, Austria: R Foundation for Statistical Computing. Retrieved from http://cran.r-project.org/

Schwaiger, F., Poschenrieder, W., Biber, P., \& Pretzsch, H. (2019). Ecosystem service trade-offs for adaptive forest management. Ecosystem Services, 39, 100993.

Seidl, R., Thom, D., Kautz, M., Martin-Benito, D., Peltoniemi, M., Vacchiano, G., . . Honkaniemi, J. (2017). Forest disturbances under climate change. Nature Climate Change, 7(6), 395-402.

Shao, G., Schall, P., \& Weishampel, J. F. (1994). Dynamic simulations of mixed broadleaved-Pinus koraiensis forests in the Changbaishan Biosphere Reserve of China. Forest Ecology and Management, 70(1-3), 169-181.

Shipley, B. (2009). Confirmatory path analysis in a generalized multilevel context. Ecology, 90(2), 363-368.

Simonin, K., Kolb, T. E., Montes-Helu, M., \& Koch, G. W. (2007). The influence of thinning on components of stand water balance in a ponderosa pine forest stand during and after extreme drought. Agricultural and Forest Meteorology, 143(3-4), 266-276.

Sipe, T., \& Bazzaz, F. (1995). Gap partitioning among maples (Acer) in central New England: survival and growth. Ecology, 76(5), 1587-1602.

Soliveres, S., Van Der Plas, F., Manning, P., Prati, D., Gossner, M. M., Renner, S. C., . . Binkenstein, J. (2016). Biodiversity at multiple trophic levels is needed for ecosystem multifunctionality. Nature, 536(7617), 456-459.

Sommerfeld, A., Senf, C., Buma, B., D'Amato, A. W., Despres, T., Diaz-Hormazabal, I., . . Seidl, R. (2018). Patterns and drivers of recent disturbances across the temperate forest biome. Nat Commun, 9(1), 4355. doi:10.1038/s41467-018-06788-9

Stone, R. (2006). A threatened nature reserve breaks down Asian borders. In: American Association for the Advancement of Science.

Thornley, J., \& Cannell, M. (2000). Managing forests for wood yield and carbon storage: a theoretical study. Tree physiology, 20(7), 477-484.

Tilman, D. (1997). The Influence of Functional Diversity and Composition on Ecosystem Processes. Science, 277(5330), 1300-1302. doi:10.1126/science.277.5330.1300

Tobner, C. M., Paquette, A., Gravel, D., Reich, P. B., Williams, L. J., \& Messier, C. (2016). Functional identity is the main driver of diversity effects in young tree communities. Ecology Letters, 19(6), 638-647. doi:10.1111/ele.12600

Van Der Heijden, M. G., Bardgett, R. D., \& Van Straalen, N. M. (2008). The unseen majority: soil microbes as drivers of plant diversity and productivity in terrestrial ecosystems. Ecol Lett, 

11(3), 296-310.

Wagg, C., Bender, S. F., Widmer, F., \& van der Heijden, M. G. (2014). Soil biodiversity and soil community composition determine ecosystem multifunctionality. Proceedings of the National Academy of Sciences, 111(14), 5266-5270.

Wang, L., Delgado-Baquerizo, M., Wang, D., Isbell, F., Liu, J., Feng, C., . . Liu, C. (2019). Diversifying livestock promotes multidiversity and multifunctionality in managed grasslands. Proc Natl Acad Sci U S A, 116(13), 6187-6192. doi:10.1073/pnas.1807354116

Wardle, D. A., Bardgett, R. D., Klironomos, J. N., Setälä, H., Van Der Putten, W. H., \& Wall, D. H. (2004). Ecological linkages between aboveground and belowground biota. Science, 304(5677), 1629-1633.

WU, Z., ZHOU, X., ZHENG, L., GAO, S., LUO, J., CAI, R., . . . WANG, X. (2008). Study on Soil Physic-chemical Properties in Natural Forest Selective Cutting Area after 10 years [J]. Journal of Mountain Science, 2.

Yachi, S., \& Loreau, M. (2007). Does complementary resource use enhance ecosystem functioning? A model of light competition in plant communities. Ecology Letters, 10(1), 54-62.

Yang, H., \& Li, F. (1985). Distribution patterns of dominant tree species on northern slope of Changbai Mountain. Research Forest Ecosystem, 5, 1-14.

Yuan, Z., Ali, A., Jucker, T., Ruiz-Benito, P., Wang, S., Jiang, L., . . . Loreau, M. (2019). Multiple abiotic and biotic pathways shape biomass demographic processes in temperate forests. Ecology, e02650. doi:10.1002/ecy.2650

Yuan, Z., Ali, A., Ruiz - Benito, P., Jucker, T., Mori, A., Wang, S., . . Wang, X. (2020). Above - and below - ground biodiversity jointly regulate temperate forest multifunctionality along a local - scale environmental gradient. Journal of Ecology.

Yuan, Z., Wang, S., Ali, A., Gazol, A., Ruiz-Benito, P., Wang, X., . . Loreau, M. (2018). Aboveground carbon storage is driven by functional trait composition and stand structural attributes rather than biodiversity in temperate mixed forests recovering from disturbances. Annals of Forest Science, 75(3), 67.

Zanne, A. E., Tank, D. C., Cornwell, W. K., Eastman, J. M., Smith, S. A., FitzJohn, R. G., . . Beaulieu, J. M. (2014). Three keys to the radiation of angiosperms into freezing environments. Nature, 506(7486), 89-92. doi:10.1038/nature12872 


\section{Figures captions}

Fig 1. The effect of disturbance intensity on forest ecosystem multifunctionality (A) and above-and below-ground biodiversity (B). Ecosystem multifunctionality includes averaged $\left(\mathrm{FEM}_{\mathrm{A}}\right), 25 \%\left(\mathrm{FEM}_{\mathrm{T} 25}\right), 50 \%\left(\mathrm{EFM}_{\mathrm{T} 50}\right)$ and $75 \%$ threshold levels $\left(\mathrm{FEM}_{\mathrm{T} 75}\right)$. Above-ground diversity includes species richness (S), Shannon-Wiener diversity of tree species $\left(\mathrm{H}_{\mathrm{S}}\right)$, Faith's phylogenetic diversity $\left(\mathrm{PD}_{\mathrm{F}}\right)$, phylogenetic species variability (PSV), functional dispersion of functional traits (FD), the first PCA axis of the community-weighted mean of six functional traits $\left(\mathrm{CWM}_{\mathrm{PC} 1}\right)$, Shannon-Wiener diversity of tree size variation $\left(\mathrm{H}_{\mathrm{D}}\right)$, and the coefficient of variation for tree $\mathrm{DBH}$ $\left(\mathrm{CV}_{\mathrm{D}}\right)$; the below-ground diversity includes, Shannon-Wiener diversity of soil bacteria $\left(\mathrm{H}_{\mathrm{B}}\right)$, and Shannon-Wiener diversity of fungi $\left(\mathrm{H}_{\mathrm{F}}\right)$. Different lowercase letters within each panel indicate significant $(P<0.5)$ differences between treatment means, after using Tukey's method to correct for multiple comparisons. Error bars represent $\pm 1 \mathrm{SE}$

Fig. 2. Effects of post-logging disturbances, climate, and above- and below-ground biodiversity on averaged ecosystem multifunctionality (A), 25\% threshold-based (B), $50 \%$ threshold-based (C), and 75\% threshold-based ecosystem multifunctionality (D).

Standardized regression coefficients of model predictors, the associated $95 \%$ confidence intervals, and the relative importance of each factor (expressed as the percentage of explained variance) are shown. The adj. $\mathrm{R}^{2}$ of the models and the $P$-value of each predictor are given as: ${ }^{*} P<0.05,{ }^{* *} P<0.01$. Dist, the disturbance levels; Clim $_{\mathrm{PC} 1}$, the first axis of 19 climate variables, whereas other abbreviations are 
716

717

718

719

720

721

722

723

724

725

726

explained in Fig. 1.

Fig.3 Results from the piece-wise structural equation models (pSEMs) exploring the direct and indirect effects of disturbance levels on forest multifunctionality at averaged (A) and three threshold levels (B-D) via above-ground diversity and below-ground diversity. Numbers adjacent to arrows are indicative of the effect size of the relationship. Continuous and dashed arrows indicate positive and negative relationships, respectively. For all relations, standardized regression coefficients and significance are given $(*<0.05, * *<0.01)$. The width of the arrows is proportional to the strength of path coefficients. $\mathrm{R}^{2}$ denotes the proportion of variance explained and model-fit statistics for each pSEM are given. 
Fig. 1

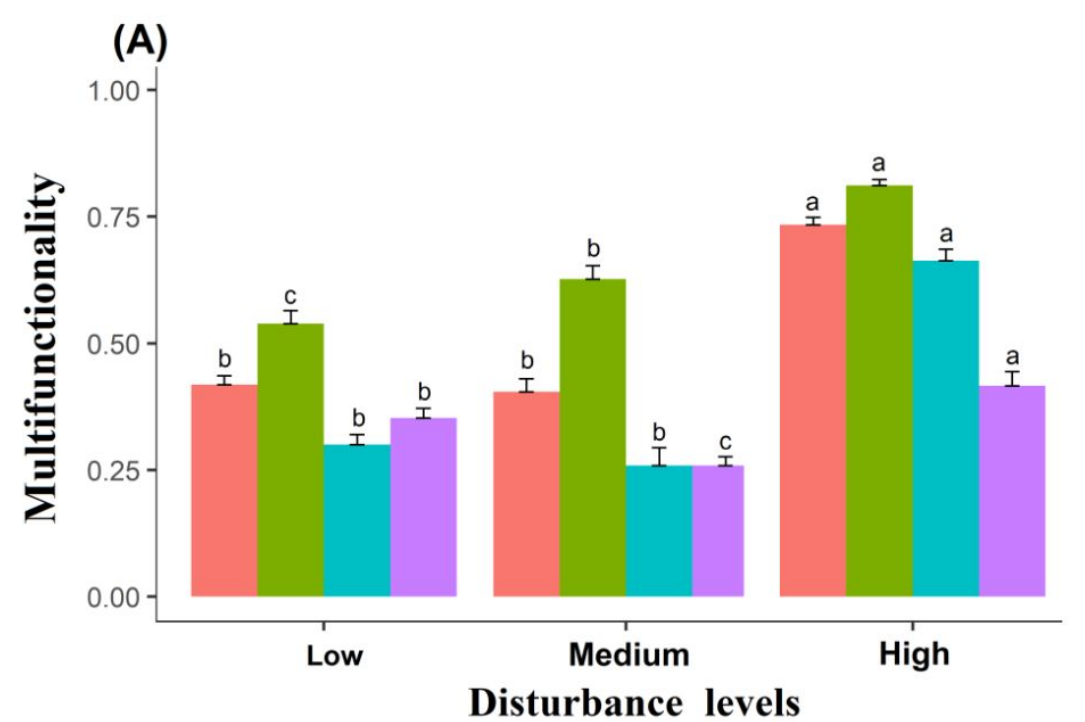
$\mathbf{E M F}_{\mathbf{A}}$
EMF $_{\text {T25 }}$
EMF $_{\text {T50 }}$
EMF $_{\text {T75 }}$

(B)

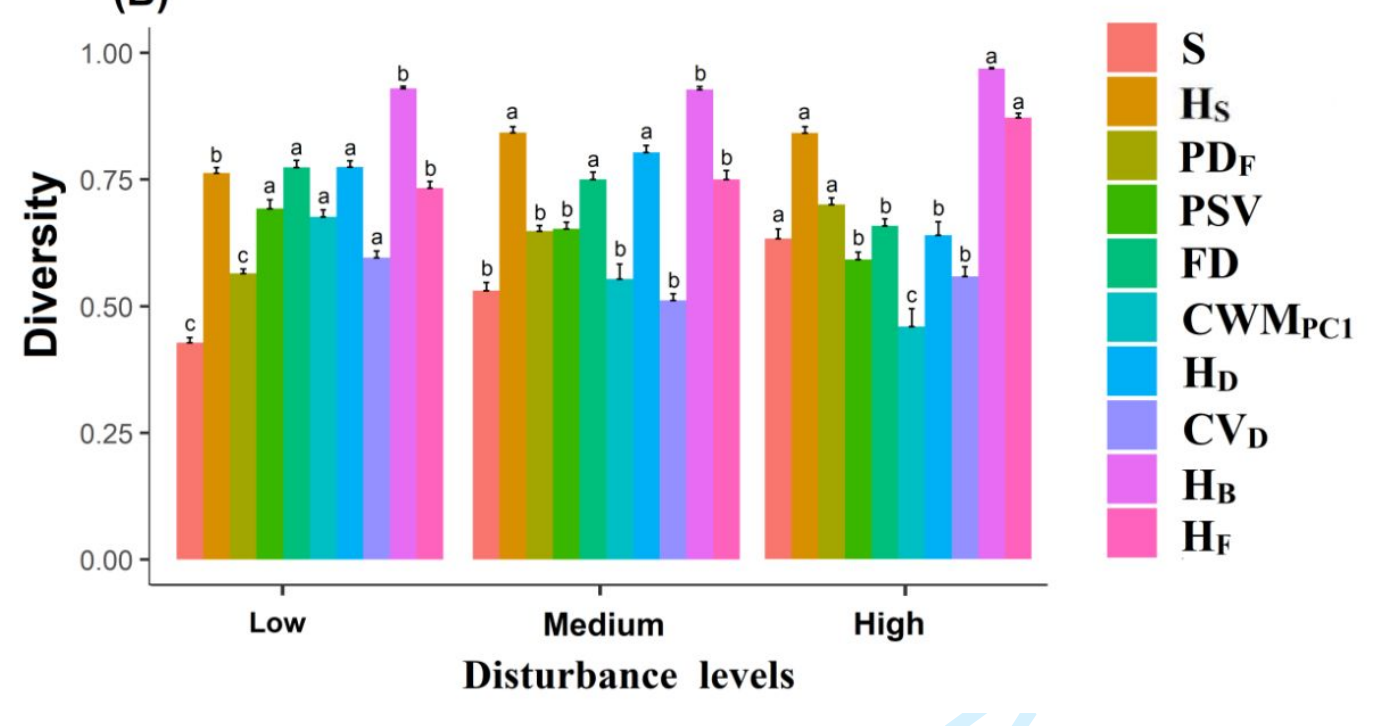


Fig. 2
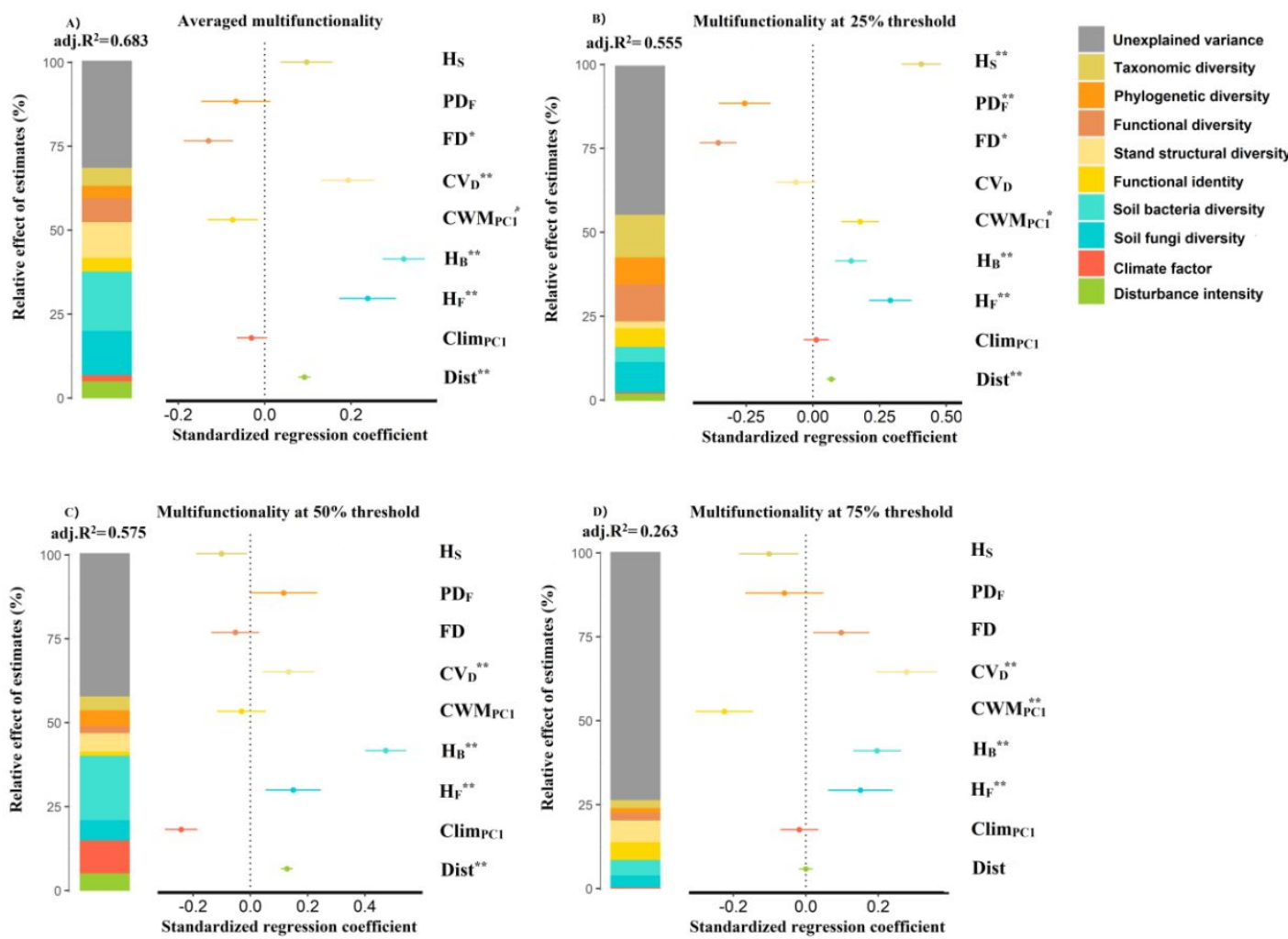


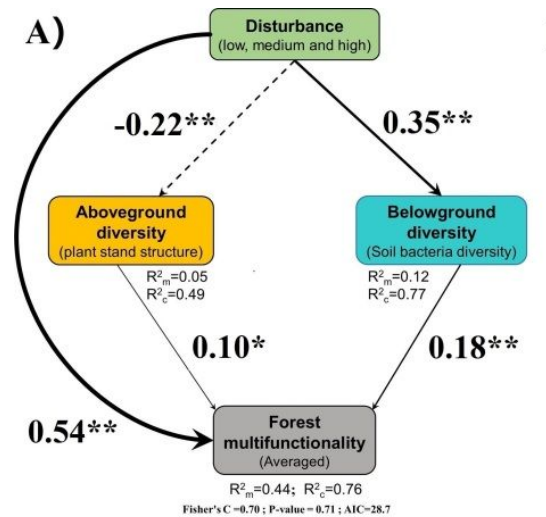

\section{Direct, indirect and total standardized effects of disturbance on EMF}
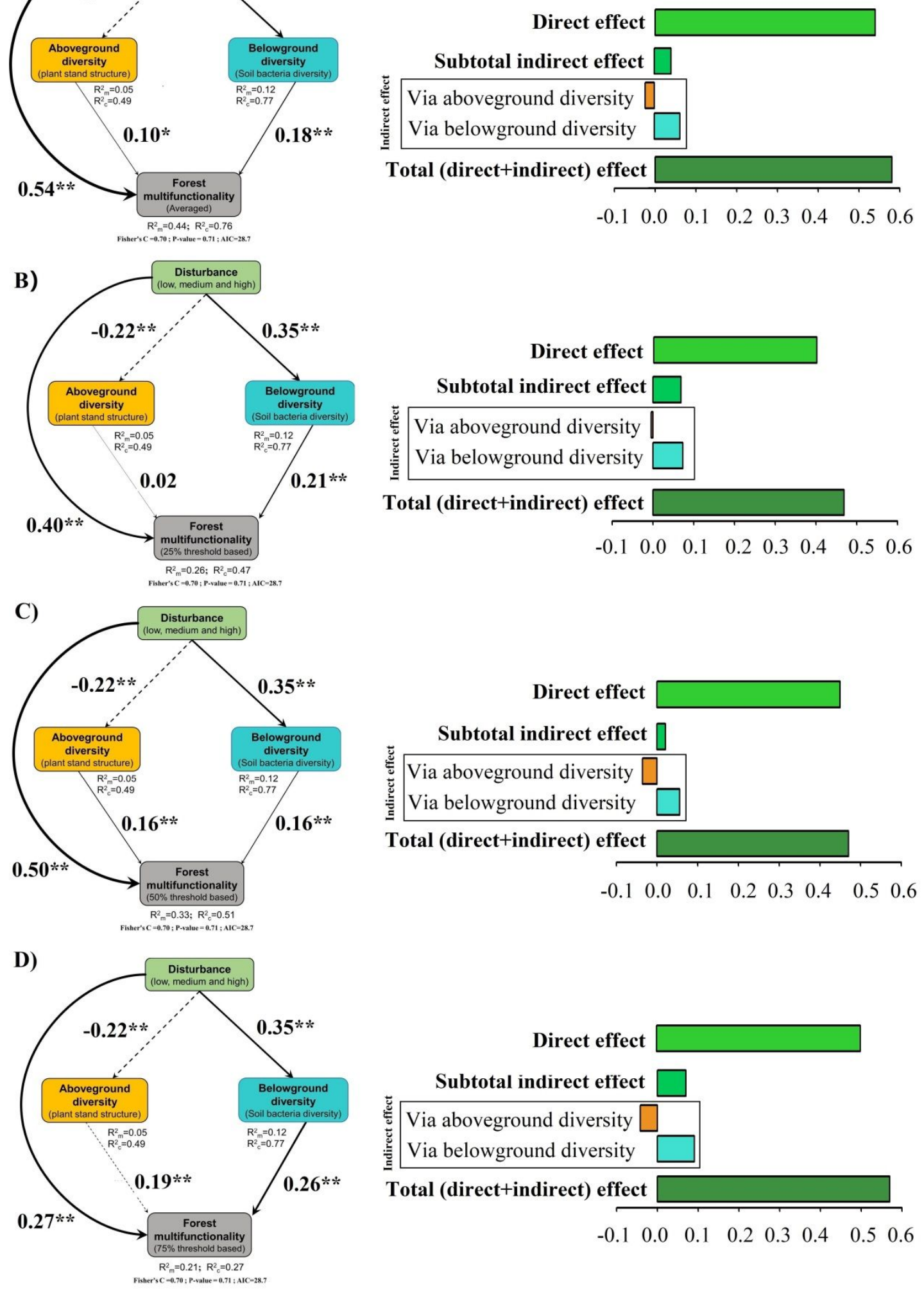